\title{
A Comprehensive Multi-Level Model for Campus-Based Leadership Education
}

\author{
David Rosch \\ Associate Professor \\ University of Illinois \\ Gayle L. Spencer \\ Director of the Illinois Leadership Center (ILC) \\ University of Illinois \\ Beth L. Hoag \\ Associate Director \\ Illinois Leadership Center \\ University of Illinois at Urbana-Champaign
}

\begin{abstract}
Within this application brief, we propose a comprehensive model for mapping the shape and optimizing the effectiveness of leadership education in campus-wide university settings. The four-level model is highlighted by inclusion of a philosophy statement detailing the values and purpose of leadership education on campus, a set of skills and competencies that serve as learning goals, a map of formal educational and informal practice opportunities for leadership development, and a plan for assessment and evaluation of effectiveness in both formative and summative contexts. We provide the example of leadership education at the University of Illinois at Urbana-Champaign to illustrate how the model might look on one campus.
\end{abstract}

\section{Introduction}

Educators in postsecondary institutions have long been faced with the challenging prospect of developing the leadership capacity of their students (Komives, 2011). Recent trends have reinforced this challenge, with renewed focus on the scholarship and practice of leadership education at universities worldwide (Dugan \& Komives, 2007). Indeed, the International Leadership Association has listed over 2,000 formal programs of leadership education at the postsecondary level (International Leadership Association, 2015). However, research is mixed on the impact of these programs on the development of students who participate within them (Dugan, 2011; Dugan et al., 2011). These results may not be surprising, given the breadth and degree of what comprises a "leadership program" within a university campus. Currently, no accepted standards or consensus exists regarding leadership education curriculum (Sowcik, et al., 2012), nor how to best connect curriculum to pedagogical methods, or even detailing the structure and context in which leadership education can or should take place (Rosch \& Kusel, 2010). Moreover, over half of the formal leadership programs participating in a national study recently described the state of their programs as either "new" or "building critical mass" (Owen, 2012), and where 64\% of programs reported relying on personality assessments such as the Myers-Briggs Type Indicator or Strengths as a foundational theoretical "leadership" model 
informing their curriculum (Owen, 2012).

Given the increased attention on leadership education, the growth in new and emerging programs, and the lack of commonly accepted standards of good practice, a need exists to describe and provide an example of a campus-wide model of leadership education for universities. We offer such a model here, which we believe should be based on a campus-wide philosophy of the values and purpose of leadership, and include: a specific and concrete set of skills and competencies associated with the behaviors of leading; a description of the various campus-based spaces and contexts where students can learn about, practice, and master such competencies; and guidelines for the formative and summative assessment of leadership education efforts on campus. We also offer, as an example, the specific model of campus-wide leadership education at the University of Illinois at Urbana-Champaign to illustrate this type of structure. To be clear, while we include the Illinois model as an exemplar, we unequivocally believe that is it the structure, not necessarily the content, of the model that we wish to impart as good practice on readers and leadership educators. The specific content and curriculum of any leadership program should be based on the unique context of each university and leadership educator (Andenoro, et al., 2013). We end this article with a discussion on how postsecondary institutions might create an inclusive process to build their own campus-wide model, again using this model as a guide.

An Overarching Structure for Leadership Education. A campus-wide multi-level model of leadership education should include four separate but overlapping classifications related to teaching, learning, and evaluation of leadership capacity delineated within the model. See Figure 1. First, the model should rest on an explicit and descriptive philosophy of leadership. Second, a set of concrete skills and competencies should be built from the philosophy espoused within the institution. Third, a blueprint should illustrate campus spaces where such skills and competencies can be learned and developed, both in formal and informal settings. Several of these settings might be explicitly focused on leadership development (e.g. formal co-curricular programs coordinated by leadership development staff), but should also include examples of where students can leverage their learning in spaces where leadership development is only a peripheral goal (or not necessarily an explicit goal at all) - such as within a classroom-based team project. Lastly, the model should include specific plans for assessing and evaluating student leadership development in the primary ways in which leadership should be measured - for formative as well as summative goals. These plans should use direct and indirect methods for helping students and educators evaluate the success of their efforts. 


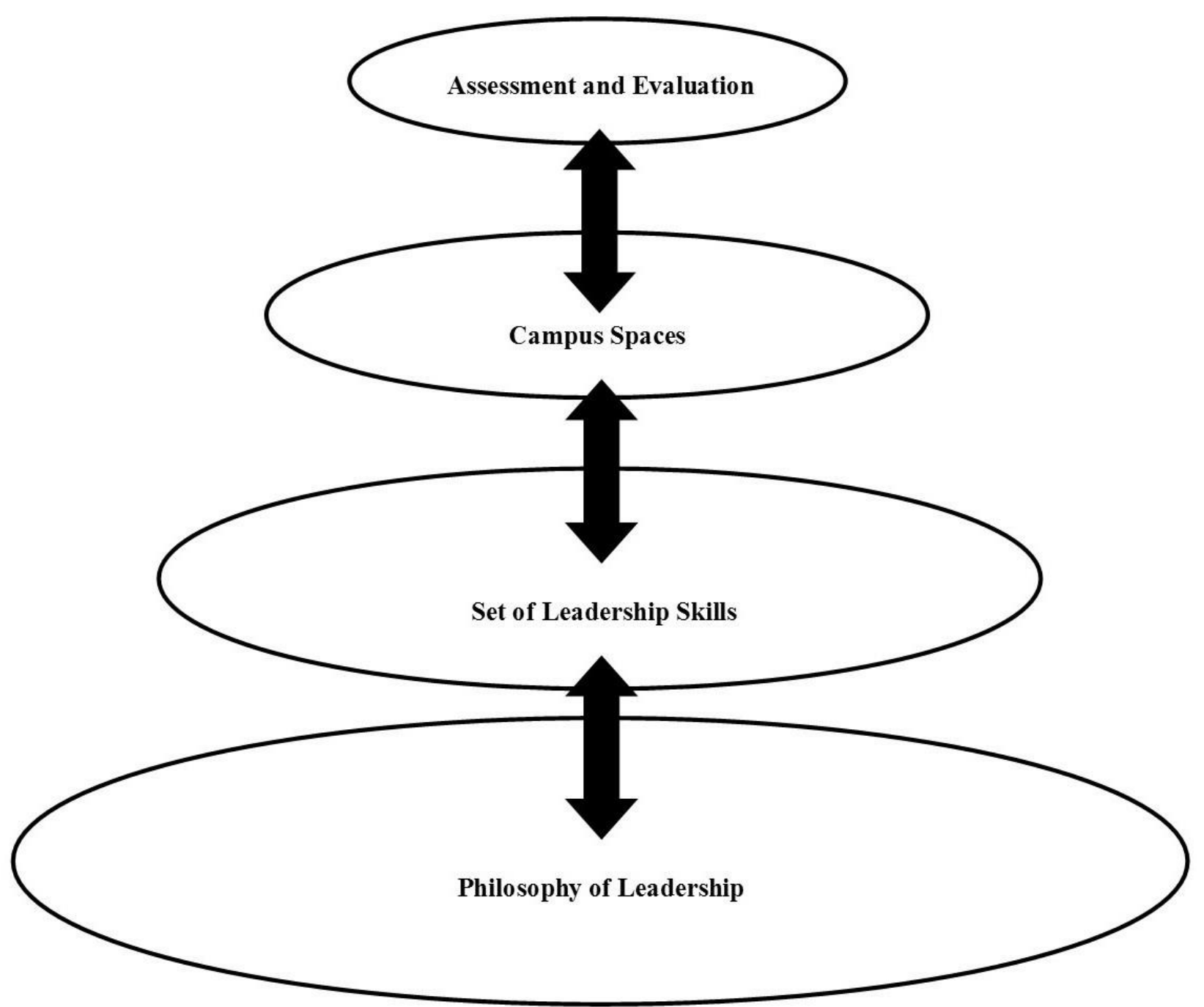

Figure 1.

A campus-wide model of leadership education

Within a model that includes these multiple levels, each level informs and supports each other level. Possessing a philosophy and values, educators and students alike can work on developing a set of leadership skills and competencies with a sense of purpose and how leaders are expected to fit into a larger community. Armed with a specific set of competencies, campus spaces can be more easily and intentionally identified and leveraged for the purpose of optimizing them for leadership development. A map of campus spaces can make both selfassessments and summative assessment of the leadership development process more efficient, focused, and accurate on both the individual student and campus levels. In turn, such assessment informs administrators which campus spaces may be missing from the process of student leadership development and which competencies may need more campus and educator support. This integrative process, however, should begin with the development of an effective philosophy. 
A Philosophy of Leadership. A philosophy statement is necessary, given the ambiguity many students share regarding the effective practice of leadership (Shertzer \& Schuh, 2004; Wielkiewicz, 2000) and the continuing discussion of consensus-building around the definition of leadership in contemporary society. A philosophy statement should not simply provide a definition of leadership, however; it should describe the values that become activated in one's actions as a leader, and the purposes around which leadership in practiced. A philosophy statement should be general enough that students and educators not directly associated with leadership development can see themselves and their goals included, and it should also be concrete enough to serve as a guide for developing the types of values and behaviors the campus espouses. In general, a campus philosophy of leadership should respond to the question, "Leadership for what?" A specified philosophy provides a picture for students, faculty, and staff who may not see themselves as leaders, leadership educators, or emerging leaders, and illustrates how they can become involved. Moreover, it focuses those with substantial background in leadership education on a set of guiding principles for the practice of program and curriculum development.

At the University of Illinois, the campus-wide leadership philosophy reads: Leaders are individuals who work with others to create positive change. Leadership can be practiced by anyone interested in making a contribution, regardless of formal authority or position.

Leadership development begins with self-knowledge-understanding one's passions, motivations, strengths, limits, and personal values. Leaders are committed to continual self-discovery, reflection, and learning.

Learning to work with others is essential, since leadership never happens alone.

Leadership is exercised as members of teams, business, civic, and community organizations, and as global citizens. Leaders recognize and value the multitude of voices, opinions, experiences, and identities in our workplaces and communities, and as leaders, we work to promote greater inclusivity and respect.

At the University of Illinois, students learn and practice leadership in their academic coursework and out of classroom activities.

We do not necessarily advocate that other universities take this philosophy statement as their own. Rather, we suggest readers begin a conversation on their own campuses - across administrative boundaries and involving diverse faculty, staff, and students - that grapples with the question of which values and philosophies will undergird the specific work of leadership development on their campus. The development of a coherent and consensus-based philosophy statement should be created only after such a campus conversation.

A Set of Skills/Competencies. Effective leadership behaviors stem, in part, from an individual's ability to work with others to solve problems (Mumford, Zaccaro, Harding, Jacobs, \& Fleishman, 2000; Seemiller, 2013). Within a framework informed by one's philosophy of leadership, a discrete set of leadership-related skills that are publicized on a campus provides goals, directions, and outcomes in skill-building initiatives offered to students. If intentionally nested in the shape of scaffolds - where overarching skill sets consist of discrete groups of specific competencies - the full set of campus-supported skills provide a structure to communicate to students and educators not directly associated with leadership development how 
each skill might be related to a larger picture of development. For example, the University of Illinois lists four skill sets under which specific competencies can be developed: personal, interpersonal, organizational, and community.

Within each set, a list of five or six specific skills can be found, each of which is defined and delineated with at least two examples in different contexts. "Cultural Competency," for example, is included within the "Interpersonal" skill set, and is defined as, "the possession of skills, knowledge, and attitudes necessary to create authentic relationships with those from different cultures" and "the ability to recruit diverse membership within one's groups and teams." Examples of student behaviors associated with cultural competence at Illinois include "building relationships with people outside of one's dominant cultural group" and "explores new cultural experiences." See Figure 2 for a full list of Illinois-espoused leadership skills.

\begin{tabular}{|c|c|c|}
\hline \multicolumn{2}{|r|}{ Competency } & Description \\
\hline \multirow{6}{*}{ 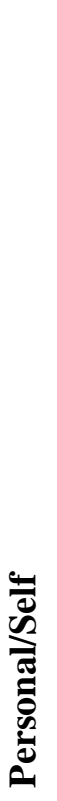 } & Self-Knowledge & $\begin{array}{l}\text { Possesses an accurate sense of one's current interests, values and goals in life; } \\
\text { Can describe one's personality, interests, strengths, and weaknesses }\end{array}$ \\
\hline & $\begin{array}{l}\text { Self- } \\
\text { Management }\end{array}$ & $\begin{array}{l}\text { Manages one's self and actions with a healthy attitude and productive } \\
\text { relationships; Consciously identifies one's goals and works towards them; Starts } \\
\text { work on one's goals and plan; Proposes new ideas or actions after consideration } \\
\text { of options }\end{array}$ \\
\hline & Reflection & $\begin{array}{l}\text { Considers past experiences and current situations to inform current and future } \\
\text { actions; Utilizes past mistakes and actions as learning opportunities to improve } \\
\text { skills }\end{array}$ \\
\hline & Empathy & $\begin{array}{l}\text { Understands the perspectives of others, without necessarily agreeing with them; } \\
\text { Recognizes and acknowledges the emotional context of interactions }\end{array}$ \\
\hline & Openness & $\begin{array}{l}\text { Values new experiences and people; Maintains a strong sense of personal values } \\
\text { while being responsive to new ones }\end{array}$ \\
\hline & Integrity & Acts to do the "right" thing consistently; Possesses a strong personal character \\
\hline \multirow{5}{*}{ 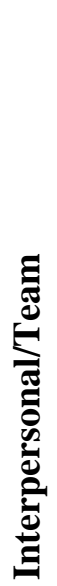 } & Commo & $\begin{array}{l}\text { Facilitates conversations within groups to agree upon goals and tactics; Builds a } \\
\text { sense of commitment from team members }\end{array}$ \\
\hline & Communication & $\begin{array}{l}\text { Shares perspectives and gathers viewpoints, in both formal and informal } \\
\text { environments; Engages in active listening }\end{array}$ \\
\hline & $\begin{array}{l}\text { Relationship } \\
\text { Management }\end{array}$ & $\begin{array}{l}\text { Builds and maintains healthy and productive relationships; Adapts personal } \\
\text { interaction style to build relationships in a variety of environments }\end{array}$ \\
\hline & Group Dynamics & $\begin{array}{l}\text { Recognizes how relationships within groups change and accordingly adapts } \\
\text { personal leadership style; Manages interpersonal conflict appropriately }\end{array}$ \\
\hline & Followership & $\begin{array}{l}\text { Supports other leaders and their initiatives; Challenges the group and other } \\
\text { leaders with respect and consideration }\end{array}$ \\
\hline
\end{tabular}




\begin{tabular}{|c|c|c|}
\hline & $\begin{array}{l}\text { Cultural } \\
\text { Competency }\end{array}$ & $\begin{array}{l}\text { Possesses the skills, knowledge, and attitude necessary to create authentic } \\
\text { relationships with those from different cultures; Recruits diverse membership } \\
\text { within groups or teams }\end{array}$ \\
\hline \multirow{4}{*}{ 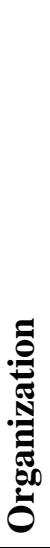 } & $\begin{array}{l}\text { Change } \\
\text { Management }\end{array}$ & $\begin{array}{l}\text { Creates successful change in organizations with a planned and disciplined } \\
\text { process; Engages others in developing a strategic future }\end{array}$ \\
\hline & $\begin{array}{l}\text { Diversity } \\
\text { Advocacy }\end{array}$ & $\begin{array}{l}\text { Promotes a culture of diversity to make organizations stronger; Advocates for } \\
\text { processes that are inclusive of diverse cultures; Creates events and celebrations } \\
\text { that teach the value of diversity of cultures }\end{array}$ \\
\hline & $\begin{array}{l}\text { Systems } \\
\text { Thinking }\end{array}$ & $\begin{array}{l}\text { Creates sustainable standard processes for ongoing tasks; Organizes the work of } \\
\text { others in a systemic and consistent manner }\end{array}$ \\
\hline & Innovation & $\begin{array}{l}\text { Values continuous assessment and improvement; Challenges the traditional } \\
\text { ways of doing things; Changes processes and structures with purpose and } \\
\text { meaning }\end{array}$ \\
\hline \multirow{5}{*}{ 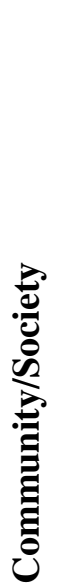 } & Human Dignity & Recognizes the worth of all people; Ensures their human rights are a priority \\
\hline & Social Justice & $\begin{array}{l}\text { Engages in opportunities to learn about privilege, and the distribution of wealth } \\
\text { and resources within a community; Strives to reduce economic, political, and } \\
\text { social inequality }\end{array}$ \\
\hline & $\begin{array}{l}\text { Global } \\
\text { Competence }\end{array}$ & $\begin{array}{l}\text { Recognizes and understands the value of global perspectives; Respects local } \\
\text { cultures within a global context }\end{array}$ \\
\hline & Service Minded & $\begin{array}{l}\text { Finds meaning in their work through service to others; Models service to others } \\
\text { by engaging in actions that serve others in and outside of their community }\end{array}$ \\
\hline & Sustainability & $\begin{array}{l}\text { Ensures the impact of work benefits the organization as well as the broader } \\
\text { society; Improves environmental conditions within their community }\end{array}$ \\
\hline
\end{tabular}

Figure 2

Competencies for effective leadership at the University of Illinois at Urbana-Champaign

Similar to our treatment of leadership philosophy, we feel that what is most significant for a campus-wide model of leadership education is not the particular skills and their descriptions listed here, but rather that each campus should be responsible for its own creation of whatever intentionally situated set of skills that is most relevant within each unique campus context. Several models of leadership practice exist that delineate specific leadership competencies (e.g. Seemiller's Competency Model (2013), the Leadership Practices Inventory (Kouzes \& Posner, 2012) among numerous others); we do not advocate for the specific adoption of any of them wholly. Rather, the process of creating a consensus-driven specific set of skills through a campus-wide conversation might be more valuable and enduring.

Campus Spaces for Learning and Practice. Once a set of discrete leadership skills have been identified, leadership educators should continue the process of model-building by identifying the spaces on their campus that can be leveraged for the development of leadership capacity in students. A list of spaces should be inclusive of the breadth of formal places to learn 
leadership (e.g. academic courses focused on leadership, skill development retreats) as well as places where students can practice leadership (e.g. student organizations, collaborative classroom projects). While we note a distinction between the learning about and practice of leadership, we also recognize the boundary can be blurred in many instances. At the same time, leadership educators (e.g. Dugan, 2011; Rosch \& Anthony, 2012) have increasingly called for the need for formal content within leadership education initiatives combined with spaces where students can practice, experiment, and develop their own skills and abilities. Some campus spaces, such as a formal leadership theory course, are optimized for learning, while others, such as a student organization, are optimized for practice. The distinction can also be important for recruiting faculty and staff who are not particularly dedicated to leadership development into the campus-wide effort to develop leadership capacity in students. For example, few chemistry faculty may consider themselves proficient or even open to providing formal leadership content in their courses. Still, when a campus-espoused model of leadership education identifies "classroom laboratories" as a space where students in pairs or small groups can practice the skills of collaboration, goal-setting, and team communication, the model provides an avenue to recruit these instructors to more intentionally support students in their development.

We feel it is not important to explicitly list every initiative and opportunity on campus. Attempting to create such an exhaustive list is time-consuming and resource-intensive; and once such effort is made, the list becomes increasingly inaccurate over time, resulting in the need for constant updating. Instead, a model should include the long-standing, durable and general institutions on campus where individual initiatives can be identified. For example, we feel it is likely more helpful to start delineating general opportunities, such as "Serving in a leadership role in a student organization" or "Seeking increasing involvement in a research lab" rather than highly specific experiences such as "Running for an executive board position in the Student Consulting Club" or "Joining Dr.___s research lab." Constructing a general list of opportunities for enduring formal learning and informal practice not only eliminates the need to continually assess the accuracy of the list of campus spaces - it also allows for further description for students about the ways that such opportunities can be leveraged given their own unique preferences and career goals.

At the University of Illinois, for example, we have created an "Illinois Leadership Inventory," (which we discuss in more depth below) where we have delineated a map of leadership development opportunities found in various classes and co-curricular experiences to our leadership competencies. The University of Illinois Leadership Center then provides part of the map in making recommendations to students wishing to gain skills in any particular competency.

Assessment and Evaluation. A campus-wide model that rests on a sound philosophy of what leadership is, includes a specific set of skills associated with its practice, and lists spaces where students can learn about and practice those skills, must also include a comprehensive blueprint for the formative and summative assessment of campus leadership development efforts (Andenoro, et al., 2013). Such a blueprint allows students the opportunity to track their own development and provides the institution the ability to accurately gauge its efforts. At the University of Illinois, we have implemented a variety of assessment methods to evaluate the effectiveness of the new model and demonstrate student growth in leadership capacity. 
In order to provide a comprehensive platform for formative assessment for students using the Illinois leadership model, we have developed the Illinois Leadership Inventory (ILI), an online self-assessment tool that allows students to reflect on their capacity for each leadership competency. The ILI has three primary goals: 1) To engage students in reflective practice and self-assessment on the Illinois Leadership Competencies; 2) Develop an inventory of leadership offerings across campus and connect students to these resources; and 3) Establish a series of metrics to assess each competency and measure individual student growth.

Students log into the ILI and select one level of practice (personal, interpersonal, organization, community) to begin the self-assessment. Next, they respond to approximately five survey items per competency regarding their recent behavior, along with an open-ended question, "Describe how you have demonstrated this competency." For example, a typical item in the "Empathy" competency is, "I actively strive to understand other perspectives and circumstances." The response set within each survey items consists of a 7-point scale ranging from "Never" to "Almost always." Scores are calculated and students are given a rating of either "beginner," "developing," or "expert" on each competency. Once a student has completed a module, they receive a report that outlines their individual strengths and areas for improvement. Students will also be provided with a series of recommendations to enhance their skills in each areas. These recommendations include course offerings, co-curricular experiences/trainings, programs offered by the Illinois Leadership Center, and books/articles or online resources.

As another example of formative assessment within the model, students enrolled in the campus-wide leadership certificate program begin their experience by completing the ILI and creating a Personal Development Plan (PDP) based on their results. Each student chooses six leadership competencies in which they want to enhance their knowledge and skills. Then they articulate a plan of action for improving their level of competence. At the end of the certificate program (after approximately 3-4 semesters, depending on the speed at which students wish to progress through the program), students create an electronic portfolio that includes reflections and artifacts that demonstrate their growth on the chosen competencies. External reviewers assess the portfolio using a rubric to demonstrate growth.

In addition to the ILI and e-portfolios, the Illinois Leadership Center assesses the effectiveness of its specific leadership training programs by conducting regular program evaluations. Each of the programs are aligned with specific leadership competencies. At the end of each program, students are asked to self-assess their growth in these related competencies. Each year one program is chosen for more in-depth analysis. The design of these assessment processes may vary by program but often include evaluative strategies such as pre-post evaluations, focus groups, and a three-month follow up survey. In addition, we use data from the Multi-Institutional Study of Leadership to compare our campus-wide efforts with those of peer institutions.

Campuses that are interested in university-wide assessment and evaluation of the leadership education efforts have numerous options aiding them in creating and maintaining a program. For example, a recent issue in New Directions in Student Leadership (Roberts \& Bailey, 2016) was dedicated to the assessment of leadership education efforts. 
Developing a Campus-wide Multi-level Model for Leadership Education. The development of a campus-wide model should include a broad cross-section of faculty, staff, and students, including those that may not consider themselves "leadership" professionals but who host opportunities for students to develop their skills nonetheless. At the University of Illinois at Urbana-Champaign, a group of approximately 50 people directly and indirectly associated with leadership education comprise the Illinois Leadership Coordinating Committee (ILCC). A subgroup of the ILCC was charged in Fall 2015 with "creating a process that results in reenvisioning campus-wide leadership education goals and metrics by connecting and collaborating with relevant campus units engaged in leadership education."

This group hosted a "leadership summit," identifying and inviting a group of over 200 faculty and staff who were in student affairs and academic affairs units that were intentionally engaged in direct or indirect leadership education. The ultimate goal was to articulate an agreedupon university-wide Leadership Development framework that reinforced or revised the existing "11 Leadership Skills and Attributes" espoused by the Illinois Leadership Center for broad campus adoption. As a result of the summit and ensuing follow-up conversations within the planning group, one of the authors coordinated the articulation of the four-classification model described above, which was then vetted by the entire ILCC. Throughout the multi-semester process, those who participated in the "leadership summit" were included and kept up-to-date on the progress of the work, and were then invited to sessions to review the new philosophy and model of leadership to provide critique and feedback. We feel that for a model to authentically be integrated into the pre-existing structures of colleges and universities, beyond the direct purview of programs and courses offered by faculty and staff explicitly responsible for leadership education, such a multi-staged and inclusive process - that moves slowly given its scope - is better for long term durability of any model over time. Leadership educators who are interested in creating a coherent campus-wide model for student leadership development should be encouraged to use this method of inclusive conversation-generation rather than a more topdown approach in their efforts.

\section{Conclusions}

We have seen an increased focus on leadership development in postsecondary education combined with a current lack of consensus on how to achieve or ensure the quality of such development. In such an environment, we propose the structure for a comprehensive model for leadership education in a university context. We feel the model provides a means of organizing how the university environment can be leveraged to optimize the opportunities for intentional student development. Our model includes a philosophy of leadership, an explicit set of competencies, a listing of spaces for learning and practicing leadership behaviors, and a plan for assessment and evaluation of developmental efforts on the student and campus unit level. As university leadership educators continue to grow and refine their programs, we feel that this model may provide a helpful blueprint for structuring such growth and refinement across a variety of university and campus settings. 


\section{References}

Andenoro, A. C., Allen, S. J., Haber-Curran, P., Jenkins, D. M., Sowcik, M., Dugan, J. P., \& Osteen, L. (2013). National leadership education research agenda 2013-2018: Providing strategic direction for the field of leadership education. Retrieved from Association of Leadership Educators website: http://leadershipeducators.org/ResearchAgenda.

Dugan, J. P. (2011). Pervasive myths in leadership development: Unpacking constraints on leadership learning. Journal of Leadership Studies, 5(2), 79-84. http://doi.org/10.1002/j1s.20223

Dugan, J. P., Bohle, C. W., Gebhardt, M., Hofert, M., Wilk, E., \& Cooney, M. a. (2011). Influences of Leadership Program Participation on Students' Capacities for Socially Responsible Leadership. Journal of Student Affairs Research and Practice, 48(1), 65-84. http://doi.org/10.2202/1949-6605.6206

Dugan, J. P., \& Komives, S. R. (2007). Developing leadership capacity in college students: Findings from a national study. A report from the Multi-Institutional Study of Leadership. College Park, MD: National Clearinghouse for Leadership Programs.

Illinois Leadership Center. http://leadership.illinois.edu.

International Leadership Association. (2015). Leadership Program Directory. Retrieved from: http://www.ila-net.org/Resources/LPD/index.htm

Komives, S. R. (2011). Advancing leadership education. In S. R. Komives, J. P. Dugan, J. Owen, W. Wagner, \& C. Slack (Eds.), The handbook for student leadership development (Vol. 2). Book Section, San Francisco: Jossey-Bass.

Kouzes, J. M., \& Posner, B. Z. (2012). The Leadership Challenge: How to Make Extraordinary Things Happen in Organizations, $5^{\text {th }} \mathrm{Ed}$. San Francisco, CA: Jossey Bass.

Multi-institutional Study of Leadership. http://www.leadershipstudy.net.

Mumford, M. D., Zaccaro, S. J., Harding, F. D., Jacobs, T. O., \& Fleishman, E. a. (2000). Leadership skills for a changing world: solving complex social problems. Leadership Quarterly, 11(1), 11-35.

Owen, J. (2012). Examining the design and delivery of collegiate student leadership development programs: Findings from the Multi-Institutional Study of Leadership (MSL-IS), a national report. Washington, DC: Council for the Advancement of Standards in Higher Education.

Roberts, D.M. \& Bailey, K.J. (2016). Assessing student leadership. In Komives, S.R. \& Guthrie, K.L. (Eds.), New directions in student leadership, Issue 151. San Francisco, CA: JosseyBass. 
Rosch, D. M., \& Anthony, M. D. (2012). Leadership Pedagogy: Putting Theory to Practice. New Directions for Student Services, 2012(140), 37-51. http://doi.org/10.1002/ss.20030

Rosch, D.M. \& Kusel, M.L. (2010). What do we mean when we talk about "leadership?" About Campus, 15(5), 29-32. DOI: 10.1002/abc.20040.

Seemiller, C. (2013). The student leadership competencies guidebook: Designing intentional leadership learning and development. New York, NY: John Wiley \& Sons.

Shertzer, J. E., \& Schuh, J. H. (2004). College student perceptions of leadership: Empowering and constraining beliefs. NASPA Journal, 42(1), 111-131.

Sowcik, M., Lindsey, J. L., \& Rosch, D. M. (2012). A collective effort to understand formalized program review. Journal of Leadership Studies, 6(3), 67-72.

Wielkiewicz, R. M. (2000). The leadership attitudes and beliefs scale: An instrument for evaluating college students' thinking about leadership and organizations. Journal of College Student Development, 41(3), 337-349.

\section{Author Biographies}

David M. Rosch is an Associate Professor and coordinates the graduate program in Agricultural Education Program at the University of Illinois. He teaches undergraduate and graduate courses in leadership theory and human capacity development, and his research is focused on the effects of leadership education on youth and emerging adults.

Gayle L. Spencer serves as the Director of the Illinois Leadership Center (ILC) at the University of Illinois at Urbana-Champaign. There she provides strategic direction for the ILC, coordinates collaborative efforts between the ILC and other academic and administrative units, and oversees all aspects of the ILC. Spencer possesses a B.S. the University of Nebraska at Omaha, her M.S. from Western Illinois University, and her Ph.D. from Kansas State University.

Beth A. Hoag is currently the Associate Director of the Illinois Leadership Center(ILC) at the University of Illinois at Urbana-Champaign. Her primary responsibilities include coordinating academic partnerships and directing research and assessment efforts. Hoag obtained her B.S. and M.A. from Bradley University, and her Ph.D in higher education administration from Bowling Green State University. 